\section{LA VACUNA CONTRA EL VIRUS DEL PAPILOMA HUMANO: ALGUNAS PRECISIONES}

\section{THE HUMAN PAPILLOMAVIRUS VACCINE: SOME PRECISIONS}

\author{
Wilfredo Gutiérrez 1 ,a
}

Sr. Editor. El cáncer de cuello uterino o cáncer cervical, representa un grave problema de salud reproductiva en la mujer, especialmente en los países en desarrollo como el nuestro. Es el tercer cáncer en importancia en el mundo y es causa de muerte en más de 250000 mujeres al año, de las cuales, más del $80 \%$ corresponden a países en desarrollo (1). En Perú, son afectadas alrededor de 5500 mujeres cada año y, de ellas, fallecen alrededor del $50 \%{ }^{(2)}$.

Un estudio realizado en 1999, estimó que alrededor del $99 \%$ de los casos de cáncer cervical en el mundo eran positivos en las pruebas que identificaban el ADN del virus del papiloma humano (VPH). Hoy se conocen unas cien cepas o serotipos del VPH, de las cuales solo unas 23 pueden afectar a las mucosas cervicales $y$, de estas, 13 son oncogénicas. Los serotipos de alto riesgo son los $6,11,16,18,31$ y 35 , que ocasionan cerca del $90 \%$ de todos los cánceres de cérvix ${ }^{(3)}$. En el Perú, las cepas más frecuentes son la 16, 18, 31 y $52{ }^{(4)}$. Sin embargo, no todas las mujeres infectadas con el VPH derivarán en cáncer cervical, pues en el $90 \%$ de casos las infecciones desaparecen sin necesidad de tratamiento. La infección persistente con cepas oncogénicas de VPH es una condición necesaria pero no suficiente para la producción de cáncer de cuello uterino. Además, deben asociarse factores de riesgo tales como el inicio precoz de las relaciones sexuales, la alta frecuencia de estas relaciones, el número elevado de parejas sexuales, la pobre higiene genital, el alto consumo de alcohol y drogas, la presencia concomitante de otras enfermedades de transmisión sexual, entre otros ${ }^{(2)}$.

La Administración de Drogas y Medicamentes de Estados Unidos (FDA por sus siglas en inglés) aprobó el 2006 una vacuna producida por Merck \& Co., Inc. (Merck) denominada Gardasil ${ }^{\mathrm{TM}}$, para prevenir la infección por las cepas $6,11,16$ y 18 del VPH, cuya eficacia se estima en un $80 \%$. Otra vacuna, Cervarix ${ }^{\mathrm{TM}}$, producida por GlaxoSmithKline (GSK) también fue aprobada por la FDA en el 2009 y protege contra dos tipos de cepas del VPH, la

1 Instituto Cuánto. Lima, Perú.

a Médico cirujano, Magíster en Salud Pública

Recibido: 19-09-11 Aprobado: 04-10-11
16 y 18 , que producen alrededor del $70 \%$ de los cánceres de cuello uterino ${ }^{(4)}$. En el 2009, ambas vacunas fueron recomendadas por la OMS para su uso generalizado en niñas adolescentes y ya se comercializan en más de cien países, incluyendo el Perú (1).

El 28 de enero de 2011 se publica el nuevo esquema de vacunación peruano, donde se incluye la vacuna contra el VPH a niñas de 10 años. Al respecto, es importante hacer algunas precisiones:

El costo de la vacuna bivalente adquirida por el fondo rotatorio de la OMS oscila entre USD 14 a 17 . Siendo entonces la vacuna contra el VPH más costosa y de menor eficacia en el esquema de vacunación peruano ( $80 \%$ frente al $95-99 \%$ de las otras vacunas).

Un reciente estudio de costo-utilidad llevado a cabo por Gutiérrez ${ }^{(4)}$ concluye que: La estrategia de tamizaje con Papanicolaou es más costo-útil que la vacunación contra el VPH, aunque las coberturas actuales solo llegan al $31 \%$. También hace la observación de que el costo anual de vacunación insume el $10 \%$ del presupuesto total asignado por el Ministerio de Economía y Finanzas en el 2010 a la estrategia sanitaria de inmunizaciones.

Basado en diferentes modelos de evaluación económica, la OMS refiere que para que la vacunación se incorpore en los esquemas regulares de los países de ingresos medios o bajos, es necesario que su costo por cada niña vacunada (incluyendo los costos del programa) sea inferior a USD $25^{(1)}$.

La vacuna no proporciona protección completa contra otros tipos de VPH, algunos de los cuales causan cáncer cervical. Por lo tanto, entre el 20 al $30 \%$ (según el tipo de vacuna) de los casos de cáncer cervical y el $10 \%$ de los casos de verrugas genitales no se prevendrán ${ }^{(5)}$; tampoco previene contra otras enfermedades de transmisión sexual ni trata la infección por VPH o el cáncer cervical.

La OMS recomienda que la introducción de la vacuna contra el VPH, deba hacerse dentro de un enfoque integral para controlar el cáncer cervical. Es decir que las mujeres sexualmente activas (vacunadas o no), deben seguir haciéndose exámenes selectivos de detección de lesiones premalignas (Papanicolau, colposcopia, despistaje de VPH) ${ }^{(1)}$.

Igualmente, es importante que se acompañe de una adecuada consejería para evitar las enfermedades de transmisión sexual como: una relación mutuamente monógama a largo plazo; evitar conductas sexuales riesgosas; usar preservativo, aunque es menos seguro 
para el VPH, ya que no protege las partes no cubiertas ${ }^{(5)}$. Por último, aparte del alto costo, debemos tener en consideración algunas cuestiones todavía no resueltas con relación a estas vacunas como el tiempo de duración de la protección; si es necesario o no administrar un refuerzo; sus efectos en la conducta sexual, sobre todo de los jóvenes y sus efectos adversos poscomercialización. Hasta junio del presente año, el Sistema de Reporte de Efectos Adversos de las Vacunas de EE.UU. (VAERS por sus siglas en inglés) había informado 18727 efectos adversos posteriores a la vacunación con Gardasil, de los cuales $8 \%$ fueron considerados serios. Entre estos se describe al síndrome de Guillain Barre; coágulos en pulmones, corazón y piernas y muerte (68 casos), aunque ninguno de estos eventos serios se ha demostrado que sean atribuibles a la vacuna ${ }^{(6)}$.

En conclusión, dado que es la vacuna más costosa y con menos eficacia relativa en el esquema de vacunación peruano, es recomendable que se aplique de manera selectiva en las escuelas ubicadas en zonas de alta prevalencia de cáncer de cuello uterino, acompañada de una adecuada información a las niñas y a sus padres sobre los beneficios y riesgos y de no descuidar las otras medidas para prevenir el cáncer de cérvix.

\section{Conflictos de interés}

El autor declara no tener conflictos de interés en la publicación de esta carta.

\section{REFERENCIAS BIBLIOGRÁFICAS}

1. World Health Organization. Strengthening cervical cancer prevention and control. Report of the GAVI-UNFPA-WHO meeting1. Geneva, Switzerland. December 2009.

2. Saona P. Cáncer de cérvix y papiloma virus humano (PVH). Lima: Sociedad Peruana de Obstetricia y Ginecología: c2006-2010.

3. Walboomers JM, Jacobs MV, Manos MM, Bosch FX, Kummer JA, Shah KV, et al. Human papillomavirus is a necessary cause of invasive cervical cancer worldwide. J Pathol. 1999;189(1):12-9.

4. Gutiérrez A. Costo utilidad de la vacuna contra el virus del papiloma humano en mujeres peruanas. Rev Peru Med Exp Salud Publica. 2011;28(3):416-25.

5. Pomfret T, Gagnon J, Gilchrist A. Quadrivalent human papillomavirus (HPV) vaccine: a review of safety, efficacy, and pharmacoeconomics. J Clin Pharm Ther. 2011;36(1):1-9.

6. Centers for Disease Control and Prevention. Reports of Health Concerns Following HPV Vaccination. Atlanta, GA: CDC; c2011.

Correspondencia: Wilfredo Gutiérrez

Dirección: Av Lima 270, Block 31 Dpto 503, Barranco

Teléfono: (+51) 989723100

Correo electrónico: gutierrw@gmail.com
INVESTIGACIÓN DE EXCELENCIA EN ALTURA: A CINCUENTA AÑOS DE LA FUNDACIÓN DEL INSTITUTO DE INVESTIGACIONES DE LA ALTURA DE LA UNIVERSIDAD PERUANA CAYETANO HEREDIA

\section{EXCELLENCE RESEARCH IN ALTITUDE: FIFTY YEARS AFTER THE FOUNDATION OF THE INSTITUTO DE INVESTIGACIONES DE LA ALTURA OF THE UNIVERSIDAD PERUANA CAYETANO HEREDIA}

\author{
Gustavo F. Gonzales ${ }^{1, a, b}$, Roger Guerra-García ${ }^{2, a}$
}

Sr. Editor. La Universidad de Ciencias Médicas y Biológicas (hoy Universidad Peruana Cayetano Heredia) se creó por Decreto Supremo el 22 de septiembre de 1961 y la primera unidad que entró en funcionamiento fue el Instituto de Investigaciones de la Altura (IIA). Este año, el IIA cumple 50 años y es importante resaltar su contribución a la salud pública del país.

En el IIA se investiga la fisiología, la patología y la epidemiología del hombre andino, así como de diversas especies animales y botánicas. Cuatro libros ${ }^{(1-4)}$ y un artículo de revisión ${ }^{(5)}$ cubren de manera amplia estos temas. Aquí destacaremos seis contribuciones que por su relevancia han sido reconocidas internacionalmente.

Eritrocitosis excesiva. En los últimos años los trabajos en el IIA han contribuido en el conocimiento de la etiopatogenia del mal de montaña crónico (MMC) y al esfuerzo internacional para conseguir un consenso para los criterios diagnósticos de dicho mal. Destaca también la colaboración entre investigadores del IIA y grupos extranjeros, en la búsqueda de alternativas médicas para el tratamiento del MMC, como el uso de la acetazolamida y los inhibidores de la enzima convertidora de angiotensina.

Patogenia de la hipertensión pulmonar hipóxica. La American Thoracic Society (ATS) otorgó el "Premio Robert F. Grover 2008" a dos investigadores del IIA por sus sobresalientes contribuciones al estudio de

\footnotetext{
Instituto de Investigaciones de la Altura, Facultad de Ciencias y Filosofía, Universidad Peruana Cayetano Heredia. Lima, Perú.

2 Instituto de Investigaciones de la Altura, Facultad de Medicina Alberto Hurtado, Universidad Peruana Cayetano Heredia. Lima, Perú.

a Doctor en Medicina; ${ }^{b}$ Doctor en Ciencias
} 